\title{
03.2
}

\section{Особенности испарения капли при лучистом и конвективном нагреве}

\author{
(C) В.А. Архипов, С.А. Басалаев, Н.Н. Золоторёв, К.Г. Перфильева , А.С. Усанина ฯ \\ Национальный исследовательский Томский государственный университет, Томск, Россия \\ I E-mail: k-g-perfiljeva@yandex.ru \\ ศศ E-mail: usaninaanna@mail.ru
}

Поступило в Редакцию 21 января 2020г.

В окончательной редакции 21 января 2020г.

Принято к публикации 27 января 2020 г.

\begin{abstract}
Предложен новый способ определения скорости испарения одиночной левитирующей капли при ее нагреве лучистым тепловым потоком. Представлены результаты экспериментального исследования скорости испарения капли дистиллированной воды при нагреве лучистым и конвективным тепловым потоком при плотности в диапазоне $q=0.25-1.5 \mathrm{~W} / \mathrm{cm}^{2}$. Проведен сравнительный анализ особенностей испарения капли при лучистом и конвективном нагреве.
\end{abstract}

Ключевые слова: капля, дистиллированная вода, лучистый тепловой поток, конвективный тепловой поток, скорость испарения, экспериментальное исследование.

DOI: 10.21883/PJTF.2020.08.49304.18209

Закономерности испарения капель играют важную роль при решении ряда прикладных задач для теплотехнических систем и технологических процессов [1,2]. Различным аспектам нагрева и испарения отдельных капель и капельных систем посвящены многочисленные публикации, связанные с численным моделированием [3-7] и экспериментальными исследованиями [8-14] процесса испарения. Большинство экспериментальных результатов исследования скорости испарения капель жидкости получено при их нагреве в условиях кондуктивного, конвективного или комбинированного радиационноконвективного теплообмена $[2,8,14]$. Скорость испарения капель определялась при их нагреве на твердой подложке $[11]$, в условиях обдува неподвижной капли высокотемпературным потоком воздуха [2,8-10], при движении капель через газообразные продукты сгорания [2,12-14] или через полый цилиндрический нагреватель $[2,12]$.

Целью настоящей работы является экспериментальное исследование особенностей испарения одиночной неподвижной капли дистиллированной воды в условиях лучистого и конвективного нагрева.

Для исследования динамики испарения одиночной капли при нагреве лучистым тепловым потоком предложен новый способ, заключающийся в определении скорости испарения неподвижной (левитирующей) капли, зафиксированной в области стоячей волны, образованной при взаимодействии прямой и отраженной звуковых волн [15]. Установка (рис. 1,a) включает ультразвуковой левитатор, содержащий пьезоэлектрический преобразователь 1 , установленный на пластину 2 и соединенный через усилитель мощности 3 с генератором колебаний 4. Акустическое поле формируется в резонаторе между пластиной 2 и отражателем 5, соединенным с микрометрическим винтом 6 для регулирования высоты резонатора. Ксеноновая лампа 7 марки ДКсР-3000М с регулируемой мощностью излучения, помещенная в фокусе параболического рефлектора 8 , используется для нагрева и подсветки левитирующей капли 9. Видеокамеры 10 марки Panasonic HDC-SD60, расположенные в перпендикулярных плоскостях, обеспечивают двухракурсную съемку испаряющейся капли 9. Перемещаемый датчик типа Ophir Optronics-FL500A для измерения плотности лучистого теплового потока (на рис. 1, $a$ не показан) установлен в месте расположения левитирующей капли.

Исследуемую каплю дистиллированной воды заданной массы с помощью капилляра помещают в резонатор и путем регулирования усилителя мощности 3 и перемещения микрометрического винта 6 добиваются ее устойчивой левитации в акустическом поле. Затем каплю удаляют, а на ее место устанавливают перемещаемый датчик теплового потока, ориентированный тепловоспринимающей поверхностью в сторону ксеноновой лампы 7. Включают ксеноновую лампу 7 при заданной мощности излучения и регистрируют величину теплового потока в этой точке резонатора. Датчик теплового потока удаляют, в резонатор помещают каплю 9 дистиллированной воды. При этом капля устойчиво фиксируется в точке резонатора, для которой проведена градуировка величины теплового потока. Видеосъемка процесса испарения капли проводится видеокамерами 10 при включенной ксеноновой лампе 7.

В данном способе локализации исходная капля приобретает вид сплющенного эллипсоида вращения. Эквивалентный радиус капли $R\left(t_{i}\right)$ в момент времени $t_{i}$ рассчитывается по формуле

$$
R\left(t_{i}\right)=0.5 \sqrt[3]{d^{2}\left(t_{i}\right) h\left(t_{i}\right)}
$$

где $d\left(t_{i}\right), h\left(t_{i}\right)$ - диаметр миделева сечения и высота деформированной капли, измеренные по видеокадрам процесса. 


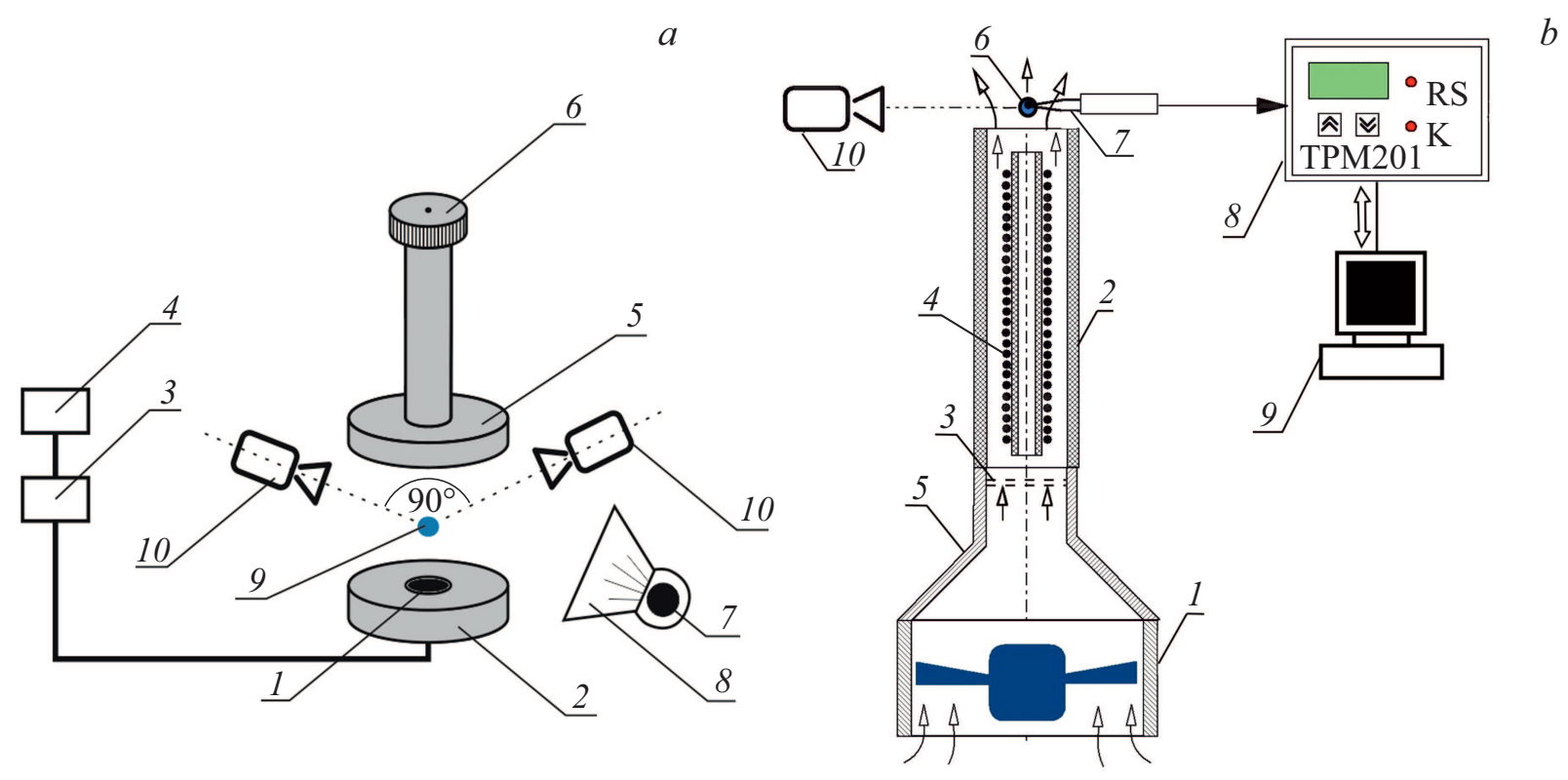

Рис. 1. Схемы экспериментальных установок для лучистого $(a)$ и конвективного $(b)$ нагрева капли. Пояснения в тексте.

Схема экспериментальной установки для исследования испарения одиночной капли при конвективном теплообмене приведена на рис. $1, b$. Для создания равномерного нагретого потока воздуха используются лопастной вентилятор 1, расположенные внутри керамической трубы 2 диафрагмы 3 и трубчатый электрический нагреватель 4. С целью увеличения скорости потока вентилятор и керамическая труба соединены конфузором 5. Температура нагревателя в диапазоне $300-550 \mathrm{~K}$ регулировалась за счет изменения мощности источника питания. Скорость потока воздуха в диапазоне $u=0-1.7 \mathrm{~m} / \mathrm{s}$ регулировалась за счет изменения напряжения, подаваемого на вентилятор. Исследуемая капля 6 с помощью шприца подвешивалась в петле хромель-копелевой термопары 7, расположенной в выходном сечении керамической трубы 2. Сигнал с термопары через усилитель 8 подавался на компьютер 9. Процесс испарения капли регистрировался видеокамерой 10 марки Panasonic HDC-SD60 при заданных параметрах среды. Скорость потока воздуха измерялась трубкой Пито, расположенной в выходном сечении керамической трубы 2, температура потока (в отсутствие капли) и температура капли в процессе испарения - термопарой 7.

Плотность конвективного теплового потока рассчитывалась по формуле

$$
q=\frac{\lambda}{2 R}\left[2+0.16\left(\frac{2 \rho u R}{\mu}\right)^{2 / 3}\right]\left(T-T_{p}\right),
$$

где $\lambda, \rho, \mu-$ коэффициент теплопроводности, плотность и коэффициент динамической вязкости воздуха при заданной температуре $T ; T$ и $T_{p}$ - температура воздуха, обдувающего каплю, и температура капли.
С использованием рассмотренных установок проведено исследование испарения капель дистиллированной воды радиусом $R=0.4-1.75 \mathrm{~mm}$. Скорость испарения капли рассчитывалась по формуле

$$
W(t)=\rho_{p} \frac{d R(t)}{d t}
$$

где $\rho_{p}$ - плотность жидкости.

На рис. 2, а показано изменение радиуса капли в условиях лучистого и конвективного нагрева при значении плотности теплового потока $q=0.25 \mathrm{~W} / \mathrm{cm}^{2}$, на рис. $2, b$ приведены зависимости скорости испарения от плотности теплового потока. Из рис. $2, b$ следует, что при фиксированном значении плотности теплового потока величина скорости испарения одиночной неподвижной капли, находящейся в условиях конвективного нагрева, превышает скорость испарения капли при лучистом нагреве. Для исследованного диапазона плотности теплового потока $q=0.25-1.5 \mathrm{~W} / \mathrm{cm}^{2}$ превышение скорости испарения составляет $\sim 75 \%$.

Поскольку на интенсивность испарения капли оказывает влияние показатель поглощения $k$ жидкости, проведены дополнительные экспериментальные исследования испарения одиночной капли дистиллированной воды в лучистом потоке при различных концентрациях сажи в дистиллированной воде. Методика эксперимента по определению зависимости показателя $k$ от концентрации сажи заключалась в следующем. С помощью ксеноновой лампы марки ДКсР-3000М создавался лучистый тепловой поток, падающий на кювету для оптических измерений, содержащую дистиллированную воду с заданным содержанием сажи. Эксперименты проведены для процентного содержания сажи $C=0-0.3 \%$. 
Показатель поглощения $k$ определялся по соотношению, следующему из закона Бугера:

$$
k=\frac{1}{l} \ln \left(\frac{I_{k}}{I_{c}}\right),
$$

где $l$ - толщина слоя жидкости, содержащей сажу (или ширина кюветы); $I_{c}-$ интенсивность излучения, прошедшего слой жидкости, содержащей сажу; $I_{k}-$ интенсивность излучения, прошедшего через пустую (без жидкости) кювету.

Обнаружено, что скорость испарения одиночной неподвижной капли линейно возрастает по мере увеличения показателя поглощения (рис. 3).

Таким образом, разработаны новые экспериментальные установки для определения характеристик испарения одиночной неподвижной капли в условиях лучистого и конвективного нагрева. Полученные результа-
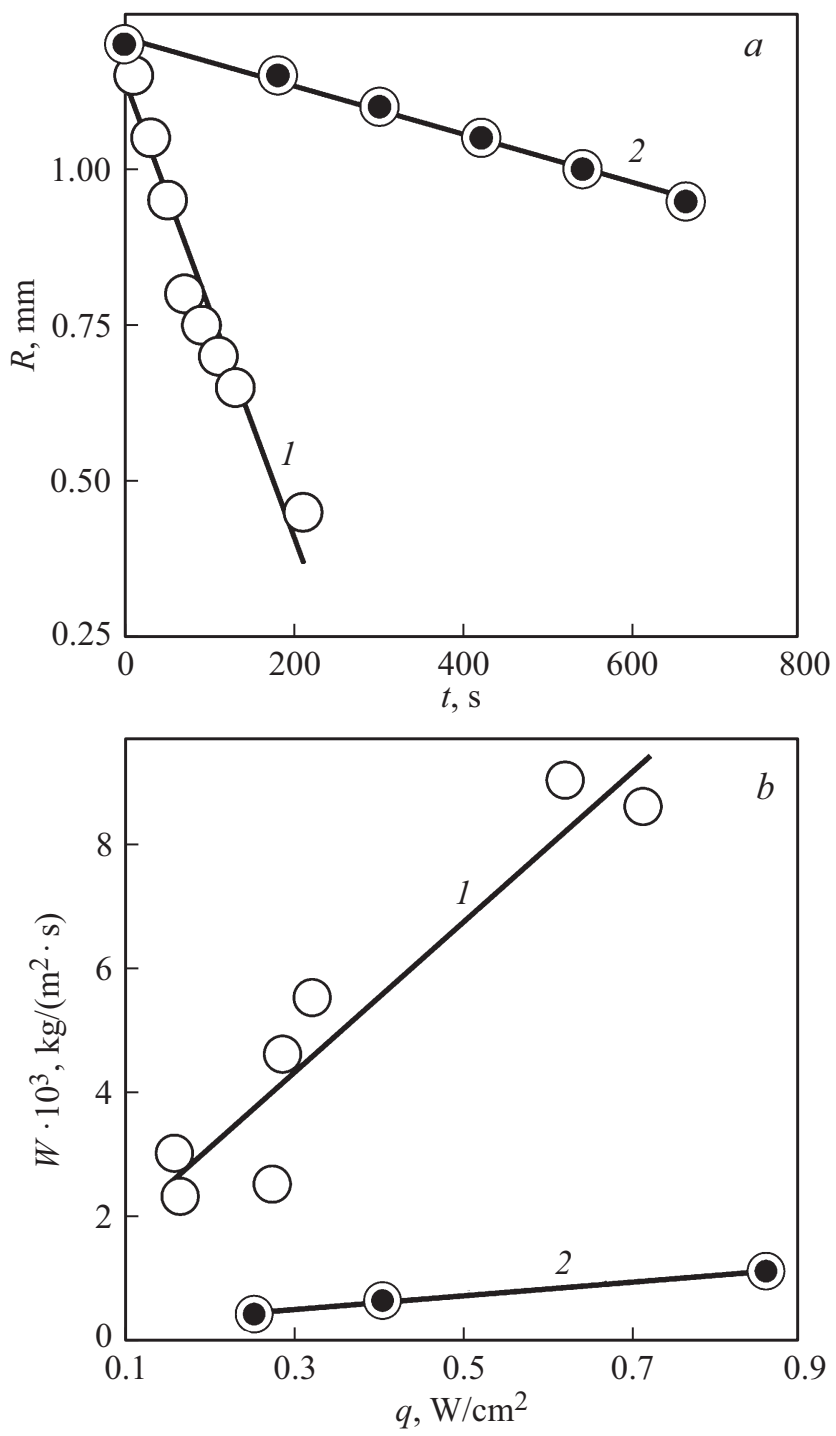

Рис. 2. Изменение радиуса капли дистиллированной воды при $q=0.25 \mathrm{~W} / \mathrm{cm}^{2}(a)$ и зависимость скорости ее испарения от плотности теплового потока $(b) .1-$ конвективный тепловой поток, 2 - лучистый тепловой поток.

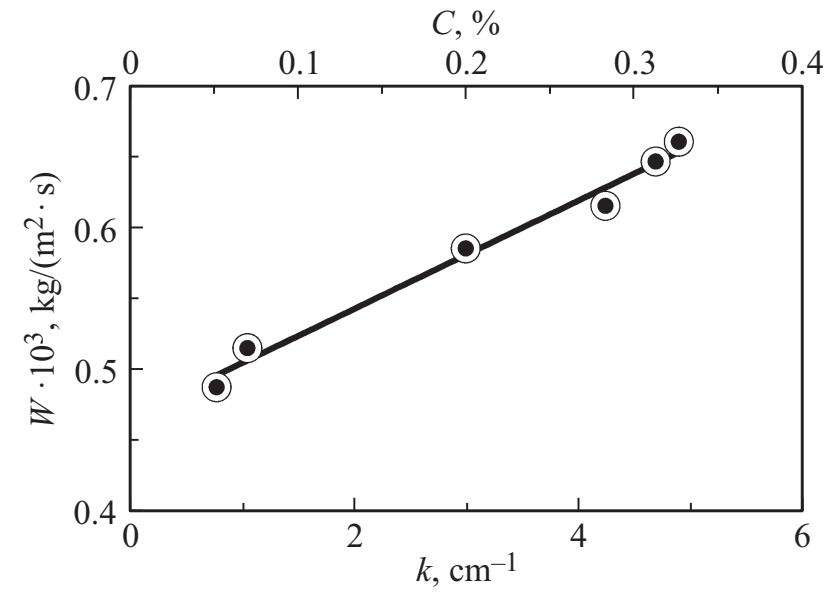

Рис. 3. Зависимость скорости испарения от содержания сажи $(C)$ в дистиллированной воде и показателя поглощения $(k)$ жидкости.

ты экспериментального исследования испарения капли дистиллированной воды согласуются в пересекающихся диапазонах определяющих параметров с результатами известных работ $[8,9,12]$ и показывают, что динамика испарения определяется механизмом нагрева, а также показателем поглощения жидкости (при лучистом нагреве). В исследованном диапазоне плотности теплового потока $q=0.25-1.5 \mathrm{~W} / \mathrm{cm}^{2}$ наблюдается превышение скорости испарения капли дистиллированной воды в условиях конвективного нагрева по сравнению со скоростью испарения капли в лучистом тепловом потоке $\sim 75 \%$.

\section{Финансирование работы}

Исследование выполнено за счет гранта Российского научного фонда (проект № 15-19-10014).

\section{Конфликт интересов}

Авторы заявляют, что у них нет конфликта интересов.

\section{Список литературы}

[1] Терехов В.И., Пахомов М.А. Тепломассоперенос и гидродинамика в газокапельных потоках. Новосибирск: Изд-во НГТУ, 2008. $284 \mathrm{c}$.

[2] Высокоморная О.В., Кузнецов Г.В., Стрижак П.А. Испарение и трансформация капель и больших массивов жидкости при движении через высокотемпературные газы. Новосибирск: Изд-во СО РАН, 2016. 302 с.

[3] Ni P. // Appl. Math. Model. 2010. V. 34. P. 2370-2376.

[4] Снегирев А.Ю., Сажин С.С., Талалов В.А. // Науч.-техн. ведомости СПбГПУ. Физ.-мат. науки. 2011. № 1. С. 44-55.

[5] Высокоморная О.В., Кузнецов Г.В., Стрижак П.А. // ИФЖ. 2016. Т. 89. № 1. С. 133-142.

[6] Wang F., Yao J., Yang S., Liu R., Jin J. // Chin. J. Aeronaut. 2017. V. 30. N 4. P. 1407-1416. 
[7] Saufi A.E., Calabria R., Chiariello F., Frassoldati A., Cuoci A., Faravelli T., Massoli P. // Chem. Eng. J. 2019. V. 375. P. $122006(1-15)$.

[8] Терехов В.И., Шишкин Н.Е., Ли Х.-К. // Современная наука: идеи, исследования, результаты, технологии. 2011. № 2. С. 215-219.

[9] Терехов В.И., Шишкин Н.Е. // Письма в ЖТФ. 2012. Т. 38. B. 1. C. $51-57$.

[10] Rivas A., Villermaux E. // Phys. Rev. Fluids. 2016. V. 1. N 1. P. $014201(1-15)$.

[11] Пискунов М.В., Стрижак П.А. // ЖТФ. 2016. Т. 86. В. 9. C. 24-31.

[12] Войтков И.С., Волков И.С., Кузнецов Г.В., Стрижсак П.А. // ЖТФ. 2017. Т. 87. В. 12. С. 1911-1914.

[13] Borodulin V.Yu., Letushko V.N., Nizovtsev M.I., Sterlyagov A.N. // Int. J. Heat Mass Transfer. 2017. V. 109. P. 609-618.

[14] Кузнецов Г.В., Стрижак П.А. // ИФЖ. 2018. Т. 91. № 1. C. $104-111$.

[15] Архипов В.А., Золоторёв Н.Н., Маслов Е.А., Кузнецов В.Т., Коноваленко А.И. Устройство для определения скорости испарения капли. Заявка № 2019131997 на патент РФ. МПК G01N 21/00. Заявл. 09.10.2019. 